\title{
Does body mass index impact the early outcome of surgical revascularization? A comparison between off-pump and on-pump coronary artery bypass grafting
}

Caliskan, Etem ; Güsewell, Sabine ; Seifert, Burkhardt ; Theusinger, Oliver M ; Starck, Christoph T ; Pavicevic, Jovana ; Reser, Diana ; Holubec, Tomas ; Plass, Andre ; Falk, Volkmar ; Emmert, Maximilian Y

\begin{abstract}
OBJECTIVES To investigate the effects of body mass index (BMI) on early outcomes after revascularization using either on-pump or off-pump surgery. METHODS Data for 3714 of 4314 patients who underwent surgical revascularization at our institution between 1999 and 2008 were analysed. Patients were divided into two groups [off-pump coronary artery bypass (OPCAB); n = 1958 and on-pump coronary artery bypass (ONCAB); $\mathrm{n}=1756]$ and further assigned into five classes according to their BMI (underweight $<20 \mathrm{~kg} / \mathrm{m}(2)$, normal $20-24.99 \mathrm{~kg} / \mathrm{m}(2)$, overweight 25-29.99 kg/m(2), obese 30-34.99 $\mathrm{kg} / \mathrm{m}(2)$ and morbidly obese $35 \mathrm{~kg} / \mathrm{m}(2))$. Thirty-day mortality, occurrence of major adverse cardiac events (MACEs), occurrence of major non-cardiac adverse events (MNCAEs) and length of in-hospital stay were analysed in relation to BMI only (whole cohort analysis), to BMI and chosen surgical method (ONCAB versus OPCAB) as well as confounding factors. RESULTS In the whole cohort analysis $(\mathrm{n}=$ 3714), no significant differences between BMI classes could be identified with regard to 30-day mortality $(\mathrm{P}=0.78)$, MACEs $(\mathrm{P}=0.72)$, MNCAEs $(\mathrm{P}=0.45)$ or length of in-hospital stay $(\mathrm{P}=0.94)$. With increasing BMI values, 30-day mortality tended to steadily increase (1.8\% in BMI class 'underweight' vs $2.6 \%$ in BMI class 'morbidly obese'; $\mathrm{P}=0.78)$, whereas MNCAEs tended to decrease with an increasing BMI (17.5\% in BMI class 'underweight' vs $12.2 \%$ in BMI class 'morbidly obese'; $\mathrm{P}=0.45)$. Compared with ONCAB, in patients with higher BMI values, OPCAB appeared to reduce slightly the frequency of 30-day mortality, MACEs and MNCAEs, while slightly increasing the length of in-hospital stay. Adjustment for other risk factors by covariate analysis in multiple regression models did not change the inferences drawn. CONCLUSIONS Our study did not detect significant differences between BMI classes with regard to mortality and morbidity. However, a slight trend towards a steadily increasing short-term mortality was detectable for patients with higher BMI values. When comparing ONCAB versus OP$\mathrm{CAB}$, patients with higher BMI values appeared to have a weak tendency towards a reduced short-term morbidity and mortality in favour of OPCAB.
\end{abstract}

DOI: https://doi.org/10.1093/icvts/ivu246

Posted at the Zurich Open Repository and Archive, University of Zurich

ZORA URL: https://doi.org/10.5167/uzh-98110

Journal Article

Originally published at:

Caliskan, Etem; Güsewell, Sabine; Seifert, Burkhardt; Theusinger, Oliver M; Starck, Christoph T; Pavicevic, Jovana; Reser, Diana; Holubec, Tomas; Plass, Andre; Falk, Volkmar; Emmert, Maximilian Y (2014). 
Does body mass index impact the early outcome of surgical revascularization? A comparison between offpump and on-pump coronary artery bypass grafting. Interactive Cardiovascular and Thoracic Surgery, 19(5):749-755.

DOI: https://doi.org/10.1093/icvts/ivu246 


\title{
Does body mass index impact the early outcome of surgical revascularization? A comparison between off-pump and on-pump coronary artery bypass grafting
}

\author{
Etem Caliskann ${ }^{a}$, Sabine Güsewell ${ }^{b}$, Burkhardt Seifertc, Oliver M. Theusinger ${ }^{d}$, Christoph T. Starck ${ }^{a}$, \\ Jovana Pavicevic ${ }^{\mathrm{a}}$, Diana Reser, ${ }^{\mathrm{a}}$, Tomas Holubec ${ }^{\mathrm{a}}$, Andre Plass ${ }^{\mathrm{a}}$, Volkmar Falk ${ }^{\mathrm{a}}$ and Maximilian Y. Emmert ${ }^{\mathrm{a}, *}$ \\ a Clinic for Cardiac Surgery, University Hospital Zurich, Zurich, Switzerland \\ b Plant Ecology, Institute of Integrative Biology, ETH Zurich, Zurich, Switzerland \\ c Division of Biostatistics, Institute for Social and Preventive Medicine, University of Zurich, Zurich, Switzerland \\ d Institute for Anaesthesiology, University Hospital Zurich, Zurich, Switzerland \\ * Corresponding author. Clinic for Cardiovascular Surgery, Raemistrasse 100, 8091 Zurich, Switzerland. Tel: +41-44-2551111; fax: +41-44-2554446; \\ e-mail: maximilian.emmert@usz.ch (M.Y. Emmert).
}

Received 16 March 2014; received in revised form 17 June 2014; accepted 24 June 2014

\begin{abstract}
OBJECTIVES: To investigate the effects of body mass index (BMI) on early outcomes after revascularization using either on-pump or offpump surgery.

METHODS: Data for 3714 of 4314 patients who underwent surgical revascularization at our institution between 1999 and 2008 were analysed. Patients were divided into two groups [off-pump coronary artery bypass (OPCAB); $n=1958$ and on-pump coronary artery bypass (ONCAB); $n=1756$ ] and further assigned into five classes according to their BMI (underweight $<20 \mathrm{~kg} / \mathrm{m}^{2}$, normal $20-24.99 \mathrm{~kg} / \mathrm{m}^{2}$, overweight $25-29.99 \mathrm{~kg} / \mathrm{m}^{2}$, obese $30-34.99 \mathrm{~kg} / \mathrm{m}^{2}$ and morbidly obese $\geq 35 \mathrm{~kg} / \mathrm{m}^{2}$ ). Thirty-day mortality, occurrence of major adverse cardiac events (MACEs), occurrence of major non-cardiac adverse events (MNCAEs) and length of in-hospital stay were analysed in relation to BMI only (whole cohort analysis), to BMI and chosen surgical method (ONCAB versus OPCAB) as well as confounding factors.

RESULTS: In the whole cohort analysis $(n=3714)$, no significant differences between BMI classes could be identified with regard to 30-day mortality $(P=0.78)$, MACEs $(P=0.72)$, MNCAEs $(P=0.45)$ or length of in-hospital stay $(P=0.94)$. With increasing BMI values, 30-day mortality tended to steadily increase (1.8\% in BMI class 'underweight' vs $2.6 \%$ in BMI class 'morbidly obese'; $P=0.78)$, whereas MNCAEs tended to decrease with an increasing BMI (17.5\% in BMI class 'underweight' vs $12.2 \%$ in BMI class 'morbidly obese'; $P=0.45$ ). Compared with $\mathrm{ONCAB}$, in patients with higher BMI values, OPCAB appeared to reduce slightly the frequency of 30-day mortality, MACEs and MNCAEs, while slightly increasing the length of in-hospital stay. Adjustment for other risk factors by covariate analysis in multiple regression models did not change the inferences drawn.
\end{abstract}

CONCLUSIONS: Our study did not detect significant differences between BMI classes with regard to mortality and morbidity. However, a slight trend towards a steadily increasing short-term mortality was detectable for patients with higher BMI values. When comparing $O N C A B$ versus $O P C A B$, patients with higher $B M I$ values appeared to have a weak tendency towards a reduced short-term morbidity and mortality in favour of OPCAB.

Keywords: Body mass index $\cdot$ Coronary artery bypass surgery $\bullet$ On-pump $\cdot$ Off-pump

\section{INTRODUCTION}

The prevalence of obesity in the USA and Europe has continuously increased during the last decades and reached epidemic proportions [1, 2].

Obesity is demonstrated as an independent risk factor and is associated with other known major risk factors/comorbidities, such as Type 2 diabetes, hypertension and dyslipidaemia for cardiovascular disease (CVD), specifically for coronary artery disease [3]. The body mass index (BMl; weight in kilograms/height ${ }^{2}$ in metres) as a surrogate measure is commonly used in obesity classification. $A B M I \geq 30.0 \mathrm{~kg} / \mathrm{m}^{2}$ defines obesity, whereas overweight is defined by a BMI value of $25.0-29.9 \mathrm{~kg} / \mathrm{m}^{2}[4,5]$.

The impact of BMI on early and late outcomes in cardiac surgery was subject to several studies with contradictory results, causing controversy over the usefulness of BMI as a predictive risk factor. Whereas most of the studies focused on the impact of BMI in patients undergoing on-pump coronary artery bypass (ONCAB) grafting surgery alone or concomitant valve procedures, little is known in the setting of off-pump coronary artery bypass (OPCAB) [6-8]. 
The aim of the present retrospective study was to investigate the effects of BMI on the early outcomes after on-pump versus off-pump surgery.

\section{MATERIALS AND METHODS}

\section{Data}

In total, 4314 patients underwent isolated surgical revascularization at our institution between 1999 and 2008 [9]. Data on weight and height as required for the calculation of $\mathrm{BMI}$ were available for 3714 patients. Patients were divided into two groups (OPCAB and $O N C A B$ ) and further assigned into five classes according to their BMI: 'underweight' (BMI $\left.<20 \mathrm{~kg} / \mathrm{m}^{2}\right)(n=57)$, 'normal' (BMI $\left.20-24.99 \mathrm{~kg} / \mathrm{m}^{2}\right)(n=991)$, 'overweight' (BMI $\left.25-29.99 \mathrm{~kg} / \mathrm{m}^{2}\right)(n=$ 1802), 'obese' (BMI $\left.30-34.99 \mathrm{~kg} / \mathrm{m}^{2}\right)(n=708)$ and 'morbidly obese' $\left(B M I \geq 35 \mathrm{~kg} / \mathrm{m}^{2}\right)(n=156)$. Among these, 1756 patients underwent ONCAB (47.3\%) and 1958 patients OPCAB (52.7\%).

Definition of BMI classes used in this analysis, number of patients per class and percentage of patients within each class treated with ONCAB and OPCAB are summarized in Table 1.

Data collection was performed prospectively and approval by the local institutional review board including waiver of informed consent was obtained. Preoperative risk stratification was performed using the European System for Cardiac Operative Risk Evaluation (EuroSCORE) risk model. Preoperative variables, demographics and assignment into BMI classes are summarized in Tables 2 and 3.

\section{Surgical technique}

ONCAB was performed in the internationally established state of the art techniques and cross-clamping of the aorta extensively described elsewhere. OPCAB was carried out as previously described [10]. In brief, after conventional median sternotomy, harvesting of the skeletonized left and right internal mammary artery and/or radial artery and/or reverse saphenous vein graft (whenever possible endoscopically) was performed as needed. A target activated clotting time $>300 \mathrm{~s}$ was aimed for by administering heparin and repeating if necessary. After opening the pericardium in a $\mathrm{T}$ fashion, pericardial stay sutures were placed for cardiac exposure. Temporary epicardial pacing wires were placed, and exposure and stabilization of the target vessel achieved by a

Table 1: Definition of BMI classes, number of patients per class and percentage of patients within each class treated with on-pump surgery (ONCAB) and off-pump surgery (OPCAB)

\begin{tabular}{lcrll} 
BMI class & $\begin{array}{l}\text { BMI range } \\
\left(\mathrm{kg} / \mathrm{m}^{2}\right)\end{array}$ & $n$ & $\begin{array}{l}\text { On-pump } \\
(\%)\end{array}$ & $\begin{array}{l}\text { Off-pump } \\
(\%)\end{array}$ \\
\hline Underweight & $<20$ & 57 & 43.9 & 56.1 \\
Normal & $20-24.99$ & 991 & 46.8 & 53.2 \\
Overweight & $25-29.99$ & 1802 & 48.4 & 51.6 \\
Obese & $30-34.99$ & 708 & 45.6 & 54.4 \\
Morbidly obese & $\geq 35$ & 156 & 46.2 & 53.8 \\
& & & &
\end{tabular}

stabilizer (Octopus4 Tissue Stabilizer; Medtronic, Inc., Minneapolis, MN, USA) and if necessary supported with a deep pericardial traction suture. Intraluminal shunts (ClearView Intracoronary Shunt; Medtronic) and a blower mister (Guidant, Indianapolis, IN, USA) with carbon dioxide and isotonic sodium chloride were used to obtain a clear surgical field routinely. Patency and flow of anastomosed grafts were routinely measured by ultrasound (MediStim QuickFit probe; MediStim ASA, Oslo, Norway) in all patients. Proximal anastomosis, if needed, was performed either by partial aortic clamping using side-biting clamps or by an aortic no-touch technique using the Heartstring device (Heartstring Proximal Seal System; Guidant).

\section{Statistical analysis}

We evaluated three binary endpoints: 30-day mortality, occurrence of major adverse cardiac events (MACEs: death, myocardial infarction, recurrent angina and stroke) and occurrence of major non-cardiac adverse events (MNCAEs: respiratory failure, renal failure and re-thoracotomy for bleeding), as well as the length of in-hospital stay, in relation to BMI. The length of in-hospital stay was analysed as a numeric response variable $(\log (x+1)$ transformed). BMI values were also log-transformed to avoid a few patients with extremely high BMI unduly influencing the regression. Relations between outcome variables and logtransformed BMI values were analysed with logistic regression (binary endpoints) or linear regression (length of in-hospital stay) and likelihood ratio tests, whereas smoothing lines from generalized additive models were represented in graphs. Relations

Table 2: Preoperative variables, demographics and risk factors/comorbidities according to the surgical technique: percentage or mean \pm SD in each of the BMI classes

\begin{tabular}{lllc} 
Factors & $\begin{array}{l}\text { On-pump } \\
(\%)\end{array}$ & $\begin{array}{l}\text { Off-pump } \\
(\%)\end{array}$ & $P$-value \\
\hline Sex: female & 17.1 & 20.0 & 0.024 \\
Age (years) & $62.7 \pm 9.7$ & $64.9 \pm 10.1$ & $<0.001$ \\
Diabetes & 21.5 & 24.5 & 0.037 \\
Smoking & 56.8 & 54.4 & 0.19 \\
Hypertension & 61.4 & 49.3 & $<0.001$ \\
Hypercholesterolaemia & 78.0 & 72.6 & 0.002 \\
Family history of coronary disease & 34.7 & 35.5 & 0.65 \\
Ejection fraction <50\% & 28.9 & 24.5 & 0.003 \\
Previous syncope & 2.3 & 2.9 & 0.41 \\
Renal disease & 1.5 & 3.7 & $<0.001$ \\
COPD & 7.4 & 5.4 & 0.013 \\
Peripheral artery disease & 13.4 & 14.6 & 0.31 \\
Left main disease & 25.3 & 30.0 & 0.002 \\
Three-vessel disease & 85.8 & 73.5 & $<0.001$ \\
Acute MI (<90 days) & 22.2 & 16.6 & $<0.001$ \\
Previous MI (>90 days) & 44.1 & 37.5 & $<0.001$ \\
Unstable angina & 19.4 & 9.9 & $<0.001$ \\
IABP preoperative & 24.2 & 10.5 & $<0.001$ \\
Urgent/emergent surgery & 35.8 & 27.6 & $<0.001$ \\
EuroSCORE & $4.0 \pm 1.2$ & $3.7 \pm 1.1$ & $<0.001$
\end{tabular}

Differences among BMI classes were tested with Pearson's chi-square test, Fisher's exact test or the Mann-Whitney test as appropriate. EuroSCORE: European System for Cardiac Operative Risk Evaluation; IABP: intra-aortic balloon pump; BMI: body mass index; COPD: chronic obstructive pulmonary disease; MI: myocardial infarction. 
Table 3: Preoperative variables, demographics and risk factors/comorbidities according to BMI class: percentage or mean \pm SD in each of the BMI classes

\begin{tabular}{|c|c|c|c|c|c|c|}
\hline Factor & Underweight & Normal & Overweight & Obese & Morbidly obese & $P$-value \\
\hline Sex: female & 38.6 & 20.3 & 15.8 & 20.1 & 26.9 & $<0.001$ \\
\hline Age (years) & $63.5 \pm 12.4$ & $64.3 \pm 10.4$ & $64.2 \pm 10.0$ & $63.0 \pm 9.1$ & $61.6 \pm 9.6$ & $<0.001$ \\
\hline Diabetes & 15.8 & 19.6 & 21.7 & 28.8 & 37.8 & $<0.001$ \\
\hline Smoking & 55.1 & 53.0 & 57.2 & 56.0 & 54.1 & 0.38 \\
\hline Hypertension & 42.1 & 49.2 & 53.7 & 65.5 & 63.5 & $<0.001$ \\
\hline Hypercholesterolaemia & 61.5 & 75.1 & 75.9 & 78.4 & 77.3 & 0.16 \\
\hline Family history of coronary disease & 22.8 & 35.2 & 35.4 & 35.0 & 36.5 & 0.41 \\
\hline Ejection fraction $<50 \%$ & 30.4 & 26.6 & 26.3 & 26.7 & 28.8 & 0.93 \\
\hline Previous syncope & 2.6 & 3.2 & 2.1 & 3.2 & 0.8 & 0.28 \\
\hline Renal disease & 2.6 & 3.4 & 1.9 & 1.9 & 2.5 & 0.22 \\
\hline COPD & 17.5 & 5.3 & 6.7 & 5.6 & 7.7 & 0.013 \\
\hline Peripheral artery disease & 23.2 & 14.6 & 14.2 & 12.9 & 10.3 & 0.15 \\
\hline Left main disease & 21.1 & 26.5 & 28.6 & 28.5 & 25.6 & 0.52 \\
\hline Three-vessel disease & 75.4 & 79.8 & 79.9 & 79.0 & 71.8 & 0.17 \\
\hline Acute $\mathrm{MI}$ (<90 days) & 8.8 & 20.9 & 19.5 & 17.5 & 17.3 & 0.11 \\
\hline Previous MI (>90 days) & 29.8 & 40.4 & 41.0 & 41.1 & 39.7 & 0.56 \\
\hline Unstable angina & 7.7 & 16.9 & 15.8 & 16.3 & 14.3 & 0.61 \\
\hline IABP preoperative & 19.3 & 16.5 & 17.7 & 15.3 & 18.6 & 0.59 \\
\hline Urgent/emergent surgery & 40.4 & 31.1 & 31.4 & 32.9 & 26.3 & 0.31 \\
\hline EuroSCORE & $3.9 \pm 1.1$ & $3.9 \pm 1.1$ & $3.8 \pm 1.1$ & $3.8 \pm 1.1$ & $3.9 \pm 1.1$ & 0.59 \\
\hline
\end{tabular}

Differences among BMI classes were tested with Pearson's chi-square test, Fisher's exact test or the Kruskal-Wallis test as appropriate. BMI: body mass index; COPD: chronic obstructive pulmonary disease; MI: myocardial infarction; IABP: intra-aortic balloon pump.

Table 4: Surgery outcomes in relation to BMI class: percentage of mortality, MACEs and MNCAEs in each BMI class and mean duration of stay in hospital, with $95 \%$ confidence intervals

\begin{tabular}{lllll} 
BMI class & Mortality (\%) & MACEs (\%) & MNCAEs (\%) & In-hospital stay (days) \\
\hline Underweight & $1.8(0.3-9.3)$ & $10.5(4.9-21.1)$ & $17.5(9.8-29.4)$ & $7.6(6.7-8.6)$ \\
Normal & $1.5(0.9-2.5)$ & $10.5(8.7-12.6)$ & $12.6(10.7-14.8)$ & $7.9(7.7-8.1)$ \\
Overweight & $2.2(1.6-2.9)$ & $12.2(10.7-13.7)$ & $14.4(12.9-16.1)$ & $7.9(7.7-8.1)$ \\
Obese & $2.0(1.2-3.3)$ & $12.1(9.9-14.8)$ & $12.4(10.2-15.1)$ & $8.0(7.7-8.3)$ \\
Morbidly obese & $2.6(1.0-6.4)$ & $10.9(6.9-16.8)$ & $12.2(7.9-18.2)$ & $8.0(7.5-8.7)$ \\
$P$-value & 0.78 & 0.72 & 0.45 & 0.94
\end{tabular}

Differences among the five BMI classes were tested with logistic regression or one-way ANOVA as appropriate. BMI: body mass index; MACE: major adverse cardiac events; MNCAE: major non-cardiac adverse events.

between outcome variables and BMI classes were analysed by calculating percentages and Wilson 95\% confidence intervals (Cls) for binary endpoints, or means and $95 \% \mathrm{Cls}$ from log-transformed data for the length of in-hospital stay. We further analysed the relation between BMI and the effect of chosen surgical method on the outcome. Odds ratios (ORs) for the effect of surgical method on outcome variables were calculated separately for each BMI class, and the significance of differences was evaluated by testing the interaction effect of BMI and surgical method in logistic or linear regression. Multiple logistic or linear regression models were used to analyse possible confounding or interactions between effects of BMI and other risk factors. First, risk factors found to be related to the BMI (Table 3) were added to the abovementioned models to check whether results are modified (confounding). Second, interaction effects between BMI and other risk factors were tested. Third, all risk factors and the BMI were subjected to an exhaustive model selection procedure based on the
Bayesian Information Criterion (BIC) to determine the five best models for the prediction of each outcome variable. The same was done with models predicting the effect of surgical method on each outcome variable. In tables with descriptive statistics, continuous data are presented as mean \pm standard deviation (SD) and differences were tested using rank sum tests. Categorical data are presented as percentages and differences were tested by Pearson's chi-square or Fisher's exact test as appropriate.

All data were analysed in the $\mathrm{R}$ programming language Version 2.12.2 (R Development Core Team, 2009) using packages bestglm and mgcv.

\section{RESULTS}

The mean $B M I$ of all analysed patients was $27.42 \pm 3.98 \mathrm{~kg} / \mathrm{m}^{2}$. The mean $\mathrm{BMI}$ in the OPCAB group was $27.47 \pm 4.03 \mathrm{~kg} / \mathrm{m}^{2}$ 
and in the ONCAB group $27.38 \pm 3.93 \mathrm{~kg} / \mathrm{m}^{2}$ without significant difference $(P=0.60)$ (Table 1).

Patients in the OPCAB group were older, more often female, and had more often diabetes, renal and gastrointestinal disease, and left main disease. Patients in the ONCAB group had more often hypertension, hypercholesterolaemia, low left ventricular ejection fraction, three-vessel disease, acute or previous myocardial infarction, and a critical preoperative state requiring intra-aortic balloon pump (IABP) and/or urgent surgery (Table 2). In general, patients with higher BMI were significantly younger and had significantly more diabetes and hypertension (Table 3). Female patients were overrepresented in the extreme $\mathrm{BMI}$ classes. No further significant relation was detected between BMI values and other risk factors/comorbidities or the EuroSCORE (Table 3).

\section{Body mass index and outcome in the whole cohort (all comers)}

For all comers, no significant differences between BMI classes could be observed with regard to 30-day mortality $(P=0.78)$, MACEs $(P=0.72)$, MNCAEs $(P=0.45)$ or length of in-hospital stay $(P=0.94)$ (Table 4$)$, and regression models only showed some tendencies but no significant relation of $\mathrm{BMI}$ values to the frequency of 30-day mortality $(P=0.24)$, MACEs $(P=0.83)$, MNCAEs $(P=0.44)$ and length of hospital stay $(P=0.55)$ (Fig. 1).

\section{Body mass index and effect of surgical method on outcome (ONCAB versus OPCAB)}

As regards surgical methods, the comparison of outcomes after $O P C A B$ versus $O N C A B$ surgery did not depend significantly on

A

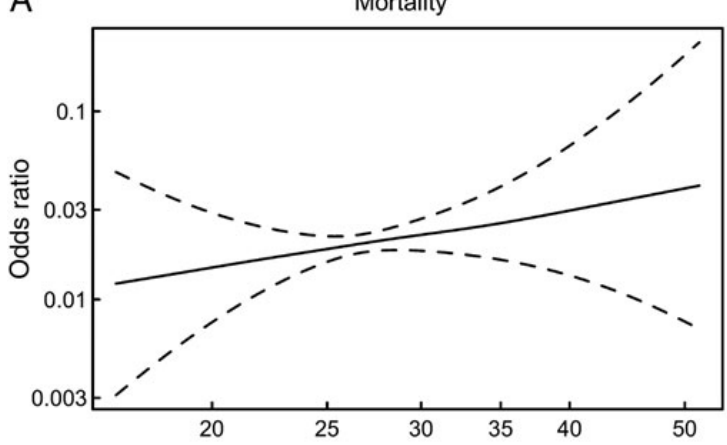

C

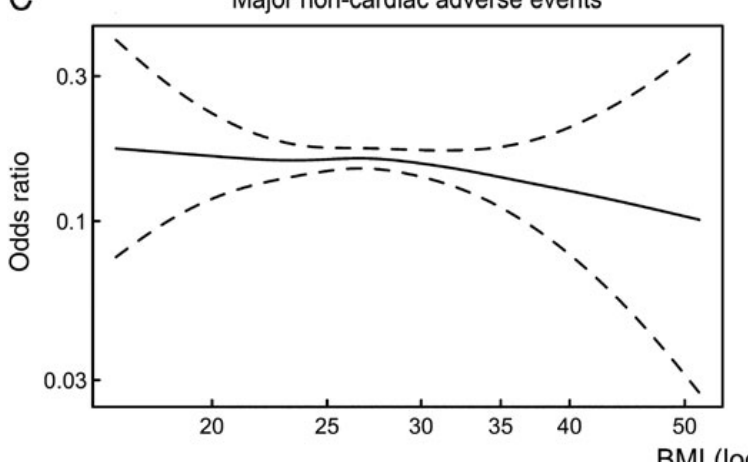

BMI (Table 5 and Fig. 2). OPCAB reduced the frequency of 30-day mortality (overall $\mathrm{OR}=0.52,95 \% \mathrm{Cl}=0.32-0.84$ ), MACEs (OR $=0.36$, $95 \% \mathrm{Cl}=0.29-0.44)$ and MNCAEs (OR $=0.43,95 \% \mathrm{Cl}=0.35-0.52)$, while increasing the length of in-hospital stay, and these effects were similar across BMI classes. In particular, obese patients (BMI $>30$ ) benefitted equally or even slightly more from OPCAB than did patients with lower BMI (Table 5 and Fig. 2).

\section{Confounding by other risk factors/interaction between effects of body mass index and other risk factors}

Adjustment for other risk factors by covariate analysis in multiple regression models hardly modified the effects of BMI classes on the outcomes or the interactive effects of BMI classes and surgical method on outcome, indicating that results were not biased by confounding effects of other risk factors (results not shown). There was also no significant interaction between the effects of BMI and other risk factors (results not shown).

The five best predictive models for each of the outcomes (found by comparing all possible models) never included the $\mathrm{BMI}$ as an explanatory variable, confirming the absence of significant relationships between $\mathrm{BMI}$ and surgical outcomes described above. Rather, the five best models for each of the outcomes included the following risk factors; the number of models (out of five) including each factor is given in parentheses.

(i) Mortality: urgent/emergent surgery (5), sex (1), hypertension (1), family history of coronary disease (1), peripheral artery disease (1)-MACE: peripheral artery disease (5), ejection fraction $<50 \%(2)$, urgent/emergent surgery (2), instable angina (1).

B

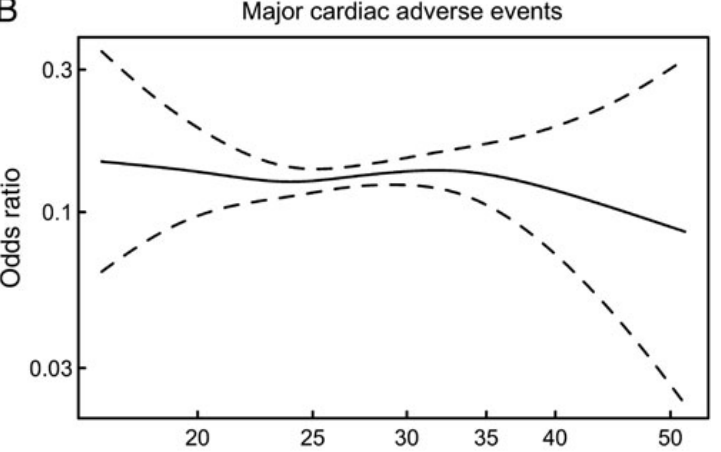

D

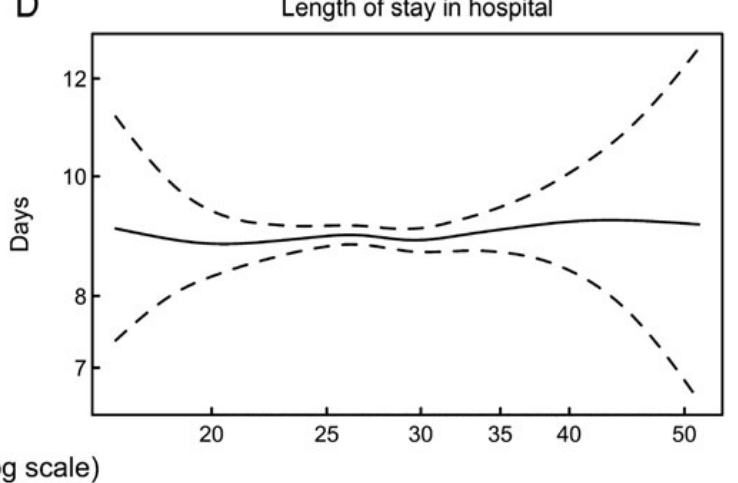

Figure 1: Relation between BMI values and surgery outcomes, that is, odds of binary endpoints (A-C) and mean duration of stay in hospital (D). Smaller values indicate better outcomes. Smoothing lines and 95\% confidence bands were fitted with generalized additive models. BMI: body mass index. 
Table 5: Effect of surgery method on outcomes in relation to BMI classes: odds ratios for the effect of off-pump versus on-pump surgery on binary endpoints, and ratios of the mean duration of stay in hospital (off-pump/on-pump) with $95 \%$ confidence intervals for each BMI class

\begin{tabular}{lllll} 
BMI class & Mortality (\%) & MACEs (\%) & MNCAEs (\%) & In-hospital stay (days) \\
\hline Overall $^{\mathrm{a}}$ & & & $0.43(0.35-0.52)$ & $1.12(1.09-1.16)$ \\
Underweight & No death & $0.36(0.29-0.44)$ & $0.27(0.06-1.16)$ & $1.02(0.79-1.32)$ \\
Normal & $0.58(0.21-1.65)$ & $0.76(0.14-4.13)$ & $0.48(0.33-0.71)$ & $1.13(1.07-1.20)$ \\
Overweight & $0.52(0.27-1.00)$ & $0.45(0.29-0.68)$ & $0.48(0.36-0.63)$ & $1.12(1.07-1.17)$ \\
Obese & $0.46(0.15-1.38)$ & $0.29(0.21-0.40)$ & $0.30(0.19-0.50)$ & $1.14(1.06-1.22)$ \\
Morbidly obese $^{\text {P-value }}$ & $0.28(0.03-2.72)$ & $0.43(0.27-0.68)$ & $0.26(0.09-0.77)$ & $1.07(0.92-1.24)$ \\
\end{tabular}

Differences among the five BMI classes were tested with logistic regression or one-way ANOVA as appropriate. MACE: major adverse cardiac events; MNCAE: major non-cardiac adverse events.

${ }^{a}$ Unadjusted overall comparison between groups.

${ }^{\mathrm{b}}$ Analysis between $\mathrm{BMI}$ classes.

A

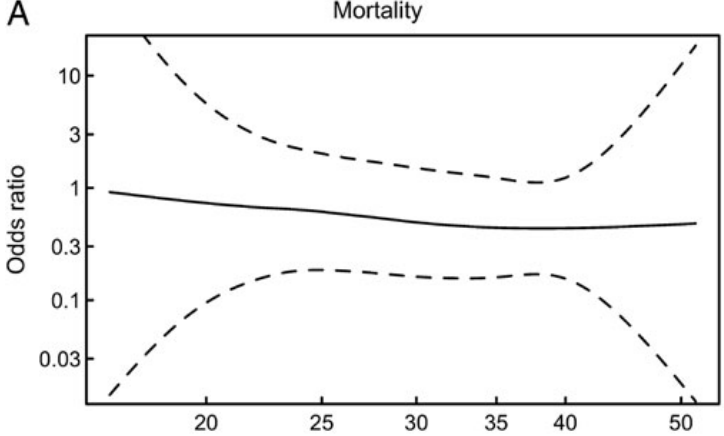

C

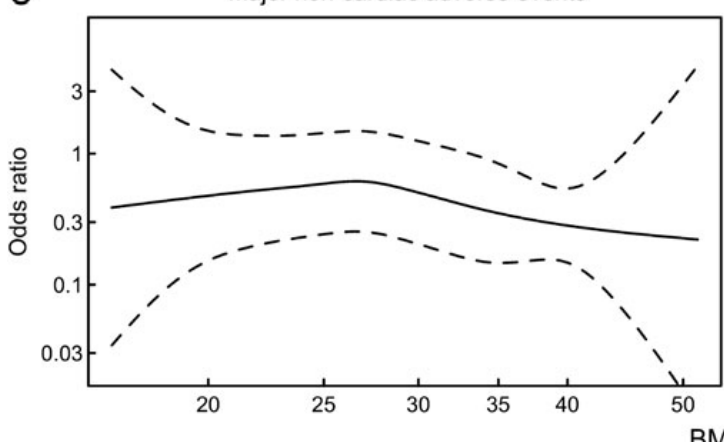

B

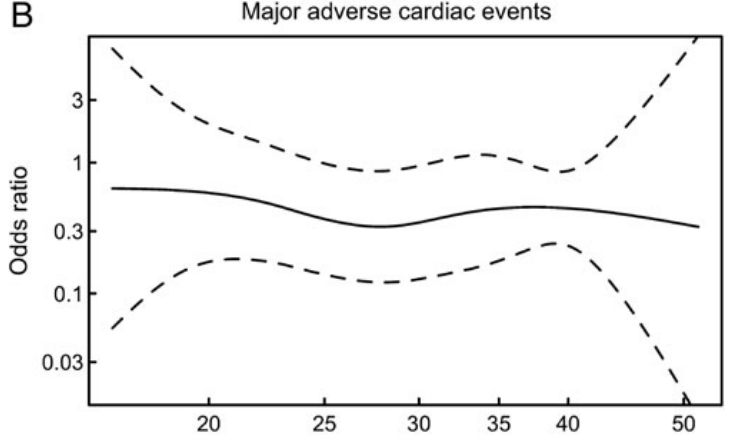

D

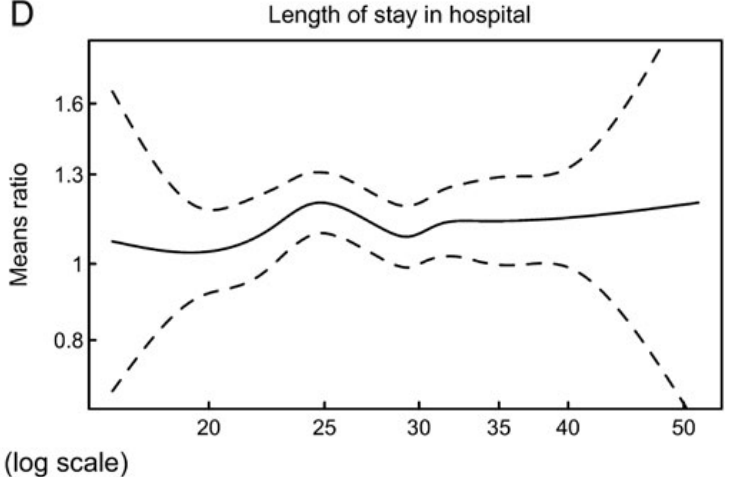

Figure 2: Relation between BMI values and the effect of surgery method (off-pump versus on-pump) on outcomes. Odds ratios (A-C) or means ratios (D) smaller than 1 indicate better outcomes with off-pump surgery. Smoothing lines and $95 \%$ confidence bands were fitted with generalized additive models. BMI: body mass index.

(ii) MNCAEs: renal disease (5), three-vessel disease (1), urgent/ emergent surgery (1), peripheral artery disease (1), IABP preoperatively (1).

(iii) Duration of stay in the hospital: urgent/emergent surgery (5), age (1), three-vessel disease (1), unstable angina (1), previous myocardial infarction (1).

\section{DISCUSSION}

Apart from the general ongoing debate about the safety and efficacy of off-pump surgery [11-13], little is known about the impact of $\mathrm{BMI}$ in the OPCAB setting. The results in this study demonstrated no major impact of BMI on early outcomes in coronary artery bypass grafting (CABG) regardless of the surgical method. Interestingly, short-term mortality, MACEs and MNCAEs appeared to be slightly reduced in OPCAB patients. Moreover, a tendency for reduced 30-day mortality and MNCAEs in favour of OPCAB patients could be observed with increasing BMI.

In a recent study on 6801 patients, Keeling et al. [8] reported a decrease of in-hospital mortality for patients with a BMI value of $<25 \mathrm{~kg} / \mathrm{m}^{2}$ after OPCAB surgery and reduced morbidity and in-hospital mortality for OPCAB patients with higher BMI values, which is in line with our results. The authors suggested a preferential benefit for patients with a low BMl by the avoidance of cardiopulmonary bypass and decreased levels of postoperative 
circulating pro-inflammatory cytokines supporting previously reported favourable data on early outcomes of the OPCAB technique in various groups of high-risk patients $[10,14,15]$.

In two other studies, Bhamidipati et al. [6] and Prapas et al. [7] investigated the impact of obesity and the influence of BMI on morbidity and mortality rates in adult patients undergoing isolated off-pump coronary artery bypass surgery. Their analysis of a limited sample size of 742 and 1359 patients, respectively, showed no significant influence of BMI on early mortality and morbidity after isolated OPCAB surgery.

By contrast, Potapov [16] reported in a large series of 22666 consecutive patients that low BMI predicts increased morbidity and mortality after cardiac surgery. Engelman et al. [17] demonstrated earlier low BMI to be an independent predictor of worse outcomes, whereas obesity itself did not predict an increase of morbidity and mortality. However, these study populations comprised mixed cardiac procedures. Similar findings were reported in a recent study on CABG-only patients [18]. Another study by van Straten et al. [19] identified underweight as a predictor for early mortality, whereas morbid obesity was a predictor for mortality. Wagner et al. [20] demonstrated in a prospective study in 80792 patients that both very low BMI and very high BMI predicted outcomes in surgical revascularization in a non-linear but U-shaped manner.

The issue of obesity and its effect on early and late mortality in CVD and specifically after surgical revascularization remains controversial. The so-called 'obesity paradox' describes a protective effect of obesity in patients with CVD in terms of better short- and long-term prognosis compared with their leaner counterparts, which is paradoxical given that obesity itself is regarded as an independent risk factor in this entity of patients [21-23].

However, regardless of chosen surgical method, our results indicated a weak but statistically non-significant tendency for increased 30-day mortality with increasing BMI values, whereas MNCAEs tended to decrease with an increasing BMI. In an analysis of 559004 patients from the Society of Thoracic Surgeons database, Prabhakar et al. [24] showed extreme obesity to be a significant predictor for adverse outcomes after CABG. Recently, Benedetto et al. [25] demonstrated in a propensity score-matched analysis that obesity did not increase operative mortality but was associated with reduced late survival in patients undergoing primary isolated $C A B G$, thus raising concerns about the 'obesity paradox'.

The present study has its limitations owing to its retrospective and non-randomized design. In addition, although a total of 4314 patients underwent surgical revascularization, only 3714 patients could be included in this study because BMI values were missing for the remaining 600 patients ( $n=14 \%$ ). Furthermore, our study cohort only contained limited numbers of patients in the extremes of BMI, i.e. patients with $\mathrm{BMI}<20.0 \mathrm{~kg} / \mathrm{m}^{2}$ and morbidly obese patients with $\mathrm{BMI} \geq 35.0 \mathrm{~kg} / \mathrm{m}^{2}$, even though these groups seem to be most controversial in the literature.

\section{Conclusions}

In summary, our study did not detect significant differences between BMI classes with regard to mortality and morbidity. However, a light trend towards a steadily increase in short-term mortality was detectable for patients with higher $B M I$ values. When comparing ONCAB versus OPCAB, patients with higher BMI values appeared to have a weak tendency towards a reduced short-term morbidity and mortality in favour of OPCAB.

\section{Funding}

This study was supported by institutional funds.

Conflict of interest: none declared.

\section{REFERENCES}

[1] Flegal KM, Carroll MD, Kit BK, Ogden CL. Prevalence of obesity and trends in the distribution of body mass index among US adults, 1999-2010. JAMA 2012;307:491-7.

[2] Berghofer A, Pischon T, Reinhold T, Apovian CM, Sharma AM, Willich SN. Obesity prevalence from a European perspective: a systematic review. BMC Public Health 2008;8:200.

[3] Poirier P, Eckel RH. Obesity and cardiovascular disease. Curr Atheroscler Rep 2002;4:448-53.

[4] Poirier P, Giles TD, Bray GA, Hong Y, Stern JS, Pi-Sunyer FX et al. Obesity and cardiovascular disease: pathophysiology, evaluation, and effect of weight loss: an update of the 1997 American Heart Association Scientific Statement on Obesity and Heart Disease from the Obesity Committee of the Council on Nutrition, Physical Activity, and Metabolism. Circulation 2006;113:898-918.

[5] National Institutes of Health. Clinical Guidelines on the Identification, Evaluation, and Treatment of Overweight and Obesity in Adults-The Evidence Report. Obesity Res 1998;6(Suppl 2):51S-209S.

[6] Bhamidipati CM, Seymour KA, Cohen N, Rolland R, Dilip KA, Lutz CJ. Is body mass index a risk factor for isolated off-pump coronary revascularization? J Card Surg 2011;26:565-71.

[7] Prapas SN, Panagiotopoulos IA, Salama Ayyad MA, Protogeros DA, Linardakis $I N$, Kotsis $V N$ et al. Impact of obesity on outcome of patients undergoing off-pump coronary artery bypass grafting using aorta no-touch technique. Interact CardioVasc Thorac Surg 2010;11: 234-7.

[8] Keeling WB, Kilgo PD, Puskas JD, Halkos ME, Lattouf OM, Guyton RA et al. Off-pump coronary artery bypass grafting attenuates morbidity and mortality for patients with low and high body mass index. J Thorac Cardiovasc Surg 2013;146:1442-8.

[9] Emmert MY, Seifert B, Wilhelm M, Grunenfelder J, Falk V, Salzberg SP. Aortic no-touch technique makes the difference in off-pump coronary artery bypass grafting. J Thorac Cardiovasc Surg 2011;142:1499-506.

[10] Emmert MY, Salzberg SP, Seifert B, Schurr UP, Hoerstrup SP, Reuthebuch $\mathrm{O}$ et al. Routine off-pump coronary artery bypass grafting is safe and feasible in high-risk patients with left main disease. Ann Thorac Surg 2010; 89:1125-30.

[11] Diegeler A, Borgermann J, Kappert U, Breuer M, Boning A, Ursulescu A et al. Off-pump versus on-pump coronary-artery bypass grafting in elderly patients. N Engl J Med 2013;368:1189-98.

[12] Lamy A, Devereaux PJ, Prabhakaran D, Taggart DP, Hu S, Paolasso E et al. Off-pump or on-pump coronary-artery bypass grafting at 30 days. N Engl J Med 2012;366:1489-97.

[13] Shroyer AL, Grover FL, Hattler B, Collins JF, McDonald GO, Kozora E et al. On-pump versus off-pump coronary-artery bypass surgery. N Engl J Med 2009:361:1827-37.

[14] Puskas JD, Thourani VH, Kilgo P, Cooper W, Vassiliades T, Vega JD et al. Off-pump coronary artery bypass disproportionately benefits high-risk patients. Ann Thorac Surg 2009;88:1142-7.

[15] Menasché $P$. The systemic factor: the comparative roles of cardiopulmonary bypass and off-pump surgery in the genesis of patient injury during and following cardiac surgery. Ann Thorac Surg 2001;72:S2260-5; discussion S2265-6, S2267-70.

[16] Potapov E. Impact of body mass index on outcome in patients after coronary artery bypass grafting with and without valve surgery. Eur Heart J 2003;24:1933-41.

[17] Engelman DT, Adams DH, Byrne JG, Aranki SF, Collins JJ, Couper GS et al. Impact of body mass index and albumin on morbidity and mortality after cardiac surgery. J Thorac Cardiovasc Surg 1999;118:866-73.

[18] Atalan N, Fazliogullari O, Kunt AT, Basaran C, Gurer O, Sitilci T et al. Effect of body mass index on early morbidity and mortality after 
isolated coronary artery bypass graft surgery. J Cardiothorac Vasc Anesth 2012;26:813-7.

[19] van Straten $A H$, Bramer $S$, Soliman Hamad $M A$, van Zundert $A A$ Martens EJ, Schonberger JP et al. Effect of body mass index on early and late mortality after coronary artery bypass grafting. Ann Thorac Surg 2010;89:30-7.

[20] Wagner BD, Grunwald GK, Rumsfeld JS, Hill JO, Ho PM, Wyatt HR et al. Relationship of body mass index with outcomes after coronary artery bypass graft surgery. Ann Thorac Surg 2007;84:10-6.

[21] Lavie CJ, Milani RV, Ventura HO. Obesity and cardiovascular disease: risk factor, paradox, and impact of weight loss. J Am Coll Cardiol 2009;53:1925-32.
[22] Engel AM, McDonough S, Smith JM. Does an obese body mass index affect hospital outcomes after coronary artery bypass graft surgery? Ann Thorac Surg 2009;88:1793-800.

[23] Taylor J. The obesity paradox. Eur Heart J 2011;32:1575-6.

[24] Prabhakar G, Haan C, Peterson E, Coombs L, Cruzzavala J, Murray G. The risks of moderate and extreme obesity for coronary artery bypass grafting outcomes: a study from the Society of Thoracic Surgeons' Database. Ann Thorac Surg 2002;74:1125-31.

[25] Benedetto U, Danese C, Codispoti M. Obesity paradox in coronary artery bypass grafting: myth or reality? J Thorac Cardiovasc Surg 2014; 147:1517-23. 